\title{
Estimated effects of climate change on flood vulnerability of U.S. bridges
}

\author{
Len Wright • Paul Chinowsky • Kenneth Strzepek • \\ Russell Jones • Richard Streeter • Joel B. Smith • \\ Jean-Marc Mayotte • Anthony Powell • \\ Lesley Jantarasami • William Perkins
}

Received: 16 May 2011 / Accepted: 20 December $2011 /$

Published online: 19 February 2012

(C) Springer Science+Business Media B.V. 2012

\begin{abstract}
We assessed the potential impacts of increased river flooding from climate change on bridges in the continental United States. Daily precipitation statistics from four climate models and three greenhouse gas (GHG) emissions scenarios (A2, A1B, and B1) were used to capture a range of potential changes in climate. Using changes in maximum daily precipitation, we estimated changes to the peak flow rates for the 100-year return period for 2,097 watersheds. These estimates were then combined with information from the National Bridge Inventory database to estimate changes to bridge scour vulnerability. The results indicate that there may be significant potential risks to bridges in the United States from increased precipitation intensities. Approximately 129,000 bridges were found to be currently deficient. Tens of thousands to more than 100,000 bridges could be vulnerable to
\end{abstract}

\author{
L. Wright \\ Independent Consultant, Boulder, CO, USA \\ P. Chinowsky \\ University of Colorado, Boulder, CO, USA \\ K. Strzepek \\ Massachusetts Institute of Technology, Cambridge, MA, USA \\ R. Jones $\cdot$ R. Streeter \\ Stratus Consulting, 1881 9th Street, Suite 201, Boulder, CO 80302, USA \\ J. B. Smith $(\bowtie)$ \\ Stratus Consulting, P.O. Box 4059, Boulder, CO 80306-4059, USA \\ e-mail: jsmith@stratusconsulting.com \\ J.-M. Mayotte \\ Independent Consultant, Fort Collins, CO, USA
}

\section{A. Powell}

Precision Water Resources Engineering, Loveland, CO, USA

L. Jantarasami $\cdot$ W. Perkins

Climate Change Division, U.S. Environmental Protection Agency, Washington, DC, USA 
increased river flows. Results by region vary considerably. In general, more bridges in eastern areas are vulnerable than those in western areas. The highest GHG emissions scenarios result in the largest number of bridges being at risk. The costs of adapting vulnerable bridges to avoid increased damage associated with climate change vary from approximately $\$ 140$ to $\$ 250$ billion through the 21 st century. If these costs were spread out evenly over the century, the annual costs would be several billion dollars. The costs of protecting the bridges against climate change risks could be reduced by approximately $30 \%$ if existing deficient bridges are improved with riprap.

Keywords Adaptation costs $\cdot$ Bridges $\cdot$ Climate change $\cdot$ Flooding

\section{Introduction}

Road bridges across the United States are a central component of the nation's transportation system. This vital role is reemphasized when disruptions occur. The partial collapse of the Oakland Bay Bridge after the 1989 Loma Prieta earthquake in the San Francisco Bay area and the collapse of the I-35 bridge in Minneapolis are two examples of how breaks in the infrastructure network can significantly disrupt what are considered to be established travel corridors. Potential climate change impacts on the nation's transportation infrastructure include inundation of the coastal transportation infrastructure by sea level rise, flooding of the coastal infrastructure by larger storm surges during hurricanes, buckling of roads and railways during heat waves, and flooding of the inland infrastructure. Two recent reports by the National Research Council (NRC 2008, 2010) highlight the broad range of vulnerabilities that U.S. infrastructure system will face during the next several decades.

The goal of this study is to determine whether estimated change in precipitation by general circulation models (GCMs) could result in changes in hydrologic and hydraulic regimes that could shorten bridge life cycles. To this end, we identify regions within the continental United States where the transportation infrastructure may be adversely impacted by increased inland flooding caused by climate change. We also estimate the magnitude of costs to adapt the at-risk infrastructure. Bridges were selected as an appropriate transportation network element because of the availability of site-specific information and their direct exposure to climatic changes. Highway bridges that cross water, ubiquitous to the highway network, are exposed to climate changes via flood events and associated changes in longterm flow regimes. The potential disruptions that could occur due to the loss of or damage to these bridges are numerous. Consequently, it is necessary to identify bridges that may be vulnerable to climate change in order to formulate proactive adaptation.

\subsection{Flooding and climate change}

The Intergovernmental Panel on Climate Change (IPCC) found that intensity of precipitation events, in particular the proportion of total precipitation that falls during heavy events, has increased and it is very likely that the proportion will continue to increase in the future (Solomon et al. 2007). The IPCC also found that higher precipitation intensity could increase the risk of flooding (Parry et al. 2007), and Wilbanks et al. (2007) identified bridges as among the infrastructure that can be at risk from climate change.

Mailhot and Duchesne (2010) examined how design criteria for urban drainage may be affected by climate change. They concluded that design criteria should factor in the expected life of the drainage system in order to maintain performance above a minimum permissible level 
of service. Savonis et al. (2009) investigated potential climate change impacts on the transportation system in the Gulf Coast area. Increases in temperature, sea level, and precipitation intensity were seen to cause an increase in the expected costs of maintaining the transportation networks and, at the same time, diminish the expected useful life of the system. Ashley et al. (2009) discussed fundamental changes to the planning and design of the drainage infrastructure in the face of climate change. They found that a more adaptable and resilient drainage system that is fundamentally altered from the current design is recommended in order to better meet the challenges of providing service under nonstationary climate conditions.

\subsubsection{Cost estimates of climate change impacts}

The existing literature on adaptation of the transportation infrastructure to climate change is primarily qualitative, with an emphasis on broad recommendations and warnings in the roads sector. These studies are primarily focused on qualitative predictions concerning road impacts on both safety and road durability. Research completed by the U.S. Transportation Research Board, the Scottish Executives, and Austroads in Australia are notable efforts in this regard (AUSTROADS 2004; Galbraith et al. 2005; TRB 2008). Within these reports, the authors compare past weather-based events with predicted climate change impacts to develop qualitative predictions. They typically project reduced life spans for roads, increased erosion of unpaved roads, and potential effects of sea level rise on coastal roads.

Recent studies have estimated costs of climate change on the infrastructure. Larsen et al. (2008) estimated approximately $\$ 24.5$ billion in net present value of maintenance and replacement costs for the transportation infrastructure through 2030 in Alaska as a result of climate impacts. Chinowsky et al. (2011a) documented the potential cost impacts of climate change on the road infrastructure in 10 geographically and economically diverse countries. The study illustrates both the potential real costs that countries may incur due to climate change scenarios, as well as the potential opportunity costs of diverting infrastructure resources to climate change adaptation. Chinowsky et al. (2011b) extended this work to address the potential effects of climate change on the entire African continent under varying climate scenarios. This study highlights the diverse physical and economic impacts that could occur throughout the area during the next several decades. The potential impact on the road infrastructure alone was more than $\$ 180$ billion.

\subsection{Adaptation strategies for bridge scour}

Most bridge failures in the United States are due to problems relating to scour (Briaud 2006). Scour causes stabilizing material, that is, the riverbed, to move away from the bridge substructure, causing instability in the bridge's foundation. A number of conditions can cause the removal, but, ultimately, scour occurs because the water flow is significant enough to move the sand or gravel away from the bridge's foundation. Hydrologists and structural engineers have studied scour for decades, and it is a central theme in bridge design references (FHWA 2001, 2009a).

As highlighted by Richardson and Lagasse (1998), several bridge collapses in the 1990s focused national attention on the issue of bridge scour. These collapses occurred in different regions and under different hydrologic conditions, highlighting the potential for scour to occur under any streambed condition. The subsequent HEC-18 (FHWA 2001) design reference focused attention on the types of scour and the relationships among flow velocity, streambed materials, and pier design in mitigating damage from scour. 


\section{Methods and data}

\subsection{Introduction}

This study involved development and application of a uniform method to estimate the number of bridges in the coterminous United States that may be vulnerable to increased freshwater flooding caused by climate change. The change in peak precipitation was analyzed using U.S. Geological Survey hydrologic unit code (HUC) levels. The highest aggregations are the 2-digit HUCs, also known as Water Resource Regions, which are displayed in Fig. 1. We estimated change in peak flow at the 8-digit HUC level. There are 2,097 8-digit HUCs in the lower 48 states.

We applied a uniform assumption to the amount of increase in peak flow that would make a bridge vulnerable. This broad screening approach made it possible to rapidly assess the potential risks arising from climate change. This approach is not meant as a substitute for a detailed bottom-up analysis, which could involve detailed basin-by-basin hydraulic analyses of changes in peak flow and site-specific conditions. Therefore, the results should be treated as a preliminary screening of bridge vulnerability and as being indicative of the potential magnitude of risks to bridges presented by climate change.

The study was based on three primary research tasks: (1) use of GCM data to develop 24-h precipitation depths at various return periods, (2) estimation of peak flows for each 8-digit HUC, and (3) identification of bridges that are most likely to be adversely affected by climate change as projected by four GCMs grouped by HUC. The following sections describe the methods used to accomplish these research tasks.

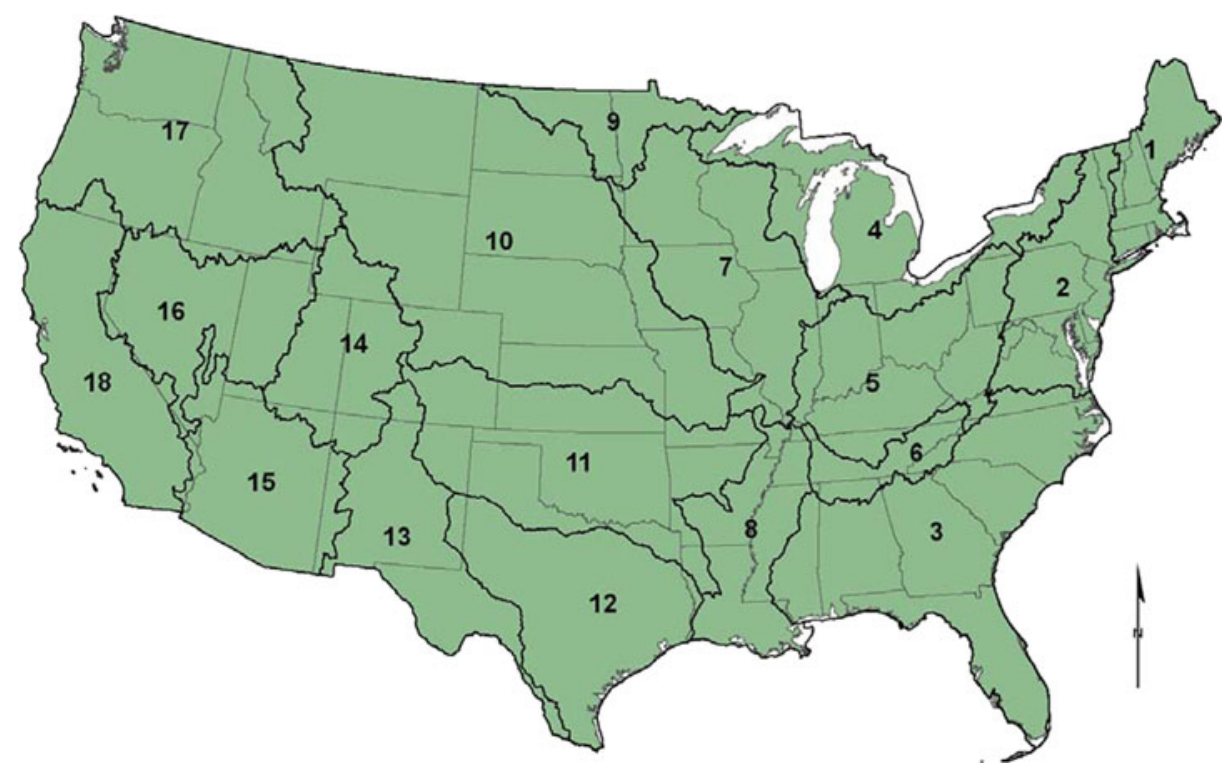

Fig. 1 Location of 2-digit HUCs. Region 1, New England; Region 2, Mid-Atlantic; Region 3, South AtlanticGulf; Region 4, Great Lakes; Region 5, Ohio; Region 6, Tennessee; Region 7, Upper Mississippi; Region 8, Lower Mississippi; Region 9, Souris-Red-Rainy; Region 10, Missouri; Region 11, Arkansas-White-Red; Region 12, Texas-Gulf; Region 13, Rio Grande; Region 14, Upper Colorado; Region 15, Lower Colorado; Region 16, Great Basin; Region 17, Pacific Northwest; Region 18, California. Source: USGS 2009 


\subsubsection{GCMs and emissions scenarios}

Four GCMs were used: CNRM-CM3, CCCMA-CGCM 3, GFDL-CM2.0, and HADCM3 (see Randall et al. 2007). All GCM data were obtained from World Climate Research Program Climate Model Intercomparison Project 3 (https://esg.1lnl.gov:8443/index.jsp). These GCMs were chosen because they were the only models available that provided changes in daily precipitation values required for the analysis at the time the study was conducted. For each GCM, three emissions scenarios were selected to illustrate possible future scenarios for resulting climate change (Nakićenovic et al. 2000). For each HUC, the GCM was averaged with eight surrounding grid cells (Hewitson 2003). This has a smoothing effect, minimizing discontinuities between grid cells. Results in terms of scour potential were then averaged across the GCMs. Analysis of individual climate models would yield more variability in results.

All models except HADCM3 provide a 20th century base run and estimates of change in daily precipitation in 2046-2065 and 2080-2100 for the A2, A1B, and B1 scenarios. The HADCM3 model (Johns et al. 2006) only had daily output available for the A2 scenario for 2080-2100. Given the limited amount of data available and that the Hadley model is generally a well-regarded climate model (e.g., Wigley 2008), data from the model were included in the study.

\subsubsection{Calculation of 100-year flows}

After a time series of GCM-estimated precipitation was obtained for the HUC, the last 20 years of data were used to determine the 100-year peak precipitation amounts for each time series. The Log Pearson Type III distribution (Stedinger et al. 1993) was used to calculate the 100-year precipitation events. This estimate of change in peak precipitation was then used to estimate a change in peak flow at the 8-digit HUC level. An important step of hydrologic modeling is to first select a model appropriate for the task at hand. This study required an estimate of peak flows from rainfall that could affect bridges. Detailed hydrologic routing was neither possible nor warranted for this study. However, an accepted method was needed to consistently simulate nonlinear watershed processes while accounting for watershed land use, soil type, and topography. Given these requirements, methods based on the U.S. Department of Agriculture's Natural Resources Conservation Service TR-20 model were used to convert 24-h rainfall "design-storm" depths to peak flows. This model is based on empirical runoff relationships referred to as the Soil Conservation Service Curve Number Method.

Design storms have been a mainstay of drainage and river engineering practices for decades. These synthetic events are used to identify both the magnitude and frequency of rainfall over periods of time that are meaningful to the infrastructure system design (ASCE 1992). A design storm is a time history of rainfall depths with specific probabilistic characteristics that are used to imply an acceptable risk level for the infrastructure investment. Although much of the literature is critical of this method for being flawed and overly simplistic when used to consider complex, multiple design objectives (see James 1994; Dent et al. 2000), the method is codified in countless municipal building and drainage requirements worldwide.

We used a design storm approach for this study for two reasons: (1) the effect of predicted climate change on design standards that are already based on design storms was desired; and (2) the method was developed to be used as an index, or proxy, that is indicative of changes in peak flow relative to historical flow. It is not intended to be used to predict the absolute magnitude of a particular frequency of event at some future point in time (e.g., the " $24-\mathrm{h}, 50$-year event in 2050").

The theoretical basis for estimating the frequencies of design storm rainfall depths from measured historical records is well established using extreme value statistics [see Stedinger 
et al. (1993) for a review of standard methods and related literature]. A time series of measured point rainfall depths is used to estimate the parameters of an extreme value distribution judged to suit the location (a Log Pearson Type III distribution is frequently used in the United States). Precipitation depths of particular frequencies needed for design may then be estimated from this parameterized distribution.

The probability density functions allow the infrastructure designer to determine an appropriate rainfall depth for a design (which implies an acceptable risk of failure of the system). This depth is then used to design the infrastructure systems and for policy decisions (ASCE 1992; Bedient et al. 2008).

\subsubsection{Infrastructure risk estimation methods}

The possible adverse effects of increased flooding on bridges range from potential catastrophic structural collapse to increased frequency of inspection and rehabilitation required to maintain a minimum level of service. We used the National Bridge Inventory (NBI) (FHWA 2009b) to identify bridges across the United States that currently meet criteria for adequacy and thus are most vulnerable to failure. This determination was made based on existing bridge conditions recorded in the NBI.

This dataset was then compared with projected increases in flow at the 100-year recurrence intervals to develop a list of bridges that, in our judgment, would face significant risks of adverse impacts. Many bridges are designed to not fail under a condition similar to, if not equal to, the 100-year, 24-h storm that was used in this study. Increases in this peak flow are indicative of more catastrophic and acute failure modes.

Significant increases in flow from the 100-year, 24-h precipitation event imply that the entire frequency distribution of flows may shift in the future. What once was a 100 -year event may be a 50 -year event in the future. The shift of the entire frequency distribution because of climate change is one of the most important implications of this study, as the life-cycle costs of maintaining a minimum level of service due to increased flow rates could be significant.

The change in peak flow from the baseline historical estimate was expressed as a ratio of future peak flow to historical peak flow. Due to limitations in the hydrologic model (TR-20 tends to be a conservative estimator of peak flows), a threshold value was used to filter out HUCs with ratios below the threshold, leaving a set of HUCs that exceeds the threshold. Based on expert judgment, threshold values were established depending on three bridge categories, as follows:

1. Currently deficient bridges: These bridges are currently in a deteriorated state and thus are more vulnerable to smaller increases in peak flows.

2. Currently acceptable bridges on sandy soils: These bridges are considered acceptable in terms of current risks but would become vulnerable to certain increases in peak flow. The increases in peak flow that would make acceptable bridges vulnerable to climate change are significantly higher than the increases that would make deficient bridges vulnerable.

3. Currently acceptable bridges on nonsandy soils: These bridges are also considered acceptable to withstand current risks but would become vulnerable if peak flows were to increase by a certain amount.

Criteria for determining vulnerability of currently deficient bridges The attributes in the NBI database were reviewed for adequacy in estimating the deficiency of bridge performance, thereby making them more vulnerable to increased flooding flows (USDOT FHA 1995). Four factors were selected from the database for this purpose, as shown below. 
1. Substructure: the physical condition of piers, abutments, piles, fenders, footings, and other components. Bridges are considered "deficient" if they are currently considered to be in "poor" condition or worse.

2. Channel and channel protection: the physical conditions associated with the flow of water under the bridge, such as stream stability, and the condition of the channel, riprap, slope protection, and stream control devices, including spur dikes. Bridges with a severe undermining of bank and embankment protection or worse were considered "deficient."

3. Waterway adequacy: the waterway opening with respect to passage of flow under the bridge. Bridges were considered deficient if the chance of being overtopped was 1 in 11 years or more frequent.

4. Vulnerability to scour: bridges are considered "deficient" to scouring if field review indicates action is required to protect exposed foundations from effects of additional erosion and corrosion or worse.

Of the four factors selected to estimate deficiency, two are indicative of the site-specific hydraulic conditions (waterway adequacy and scour potential) and two are indicative of structural bridge conditions. If a bridge failed to satisfy any factor, it was deemed to be currently deficient. The distribution of deficient bridges in the United States is shown in Fig. 2. The total number of deficient bridges is 128,722 , approximately one-fourth of the bridges in the United States.

Analysis categories We established categories from which estimates of the costs of adapting bridges could be made. Bridges were placed into an appropriate cell in Table 1. The division into sandy and nonsandy soils was based on the need to discriminate between the increase in flows required for adaptation based on streambed materials. We used methods developed by the Federal Highway Administration (FHWA 2001) and Xanthakos (1995) to estimate the change in peak flow that would increase the scour potential and result in exceeding the vulnerability threshold. We assumed a $20 \%$ increase in peak flow would make currently deficient bridges vulnerable. A larger increase in flow would be needed to make currently acceptable bridges vulnerable: a 100\% increase for bridges on sandy soils and a $60 \%$ increase for bridges on nonsandy soils. A flow of 5 feet per second (fps) on sandy soils necessitates use of riprap to protect bridges. An increase of flow to more than $9 \mathrm{fps}$, close to a $100 \%$ increase, necessitates strengthening of piers. Bridges on nonsandy soils do not need riprap until flow is $7 \mathrm{fps}$. An increase of $4 \mathrm{fps}$, about $60 \%$, necessitates strengthening of these bridges.

\subsubsection{Cost analysis}

We estimated adaptation costs in two periods: 2010-2055 and 2055-2090. The overall approach is based on recommendations from FHWA (2001) regarding bridge scour mitigation. Two levels of adaptation were analyzed based on change in flow. At a lower level of increased flow, riprap is used to stabilize bridges. If the increase in flows exceeds the maximum recommended level for riprap during a cost period, then the bridge piers and abutments are strengthened with additional concrete.

We assumed that a $20 \%$ increase in flow would necessitate putting in riprap and we assumed riprap would be put in for all bridges (Chinowsky et al. 2009). This threshold was based on historical evidence that adaptation to natural processes typically occurs after a $20 \%$ decrease in potential life span or after a $20 \%$ increase in natural activity occurs in a given scenario, such as a flood or earthquake (see also Larsen et al. 2008). We also assumed that if 


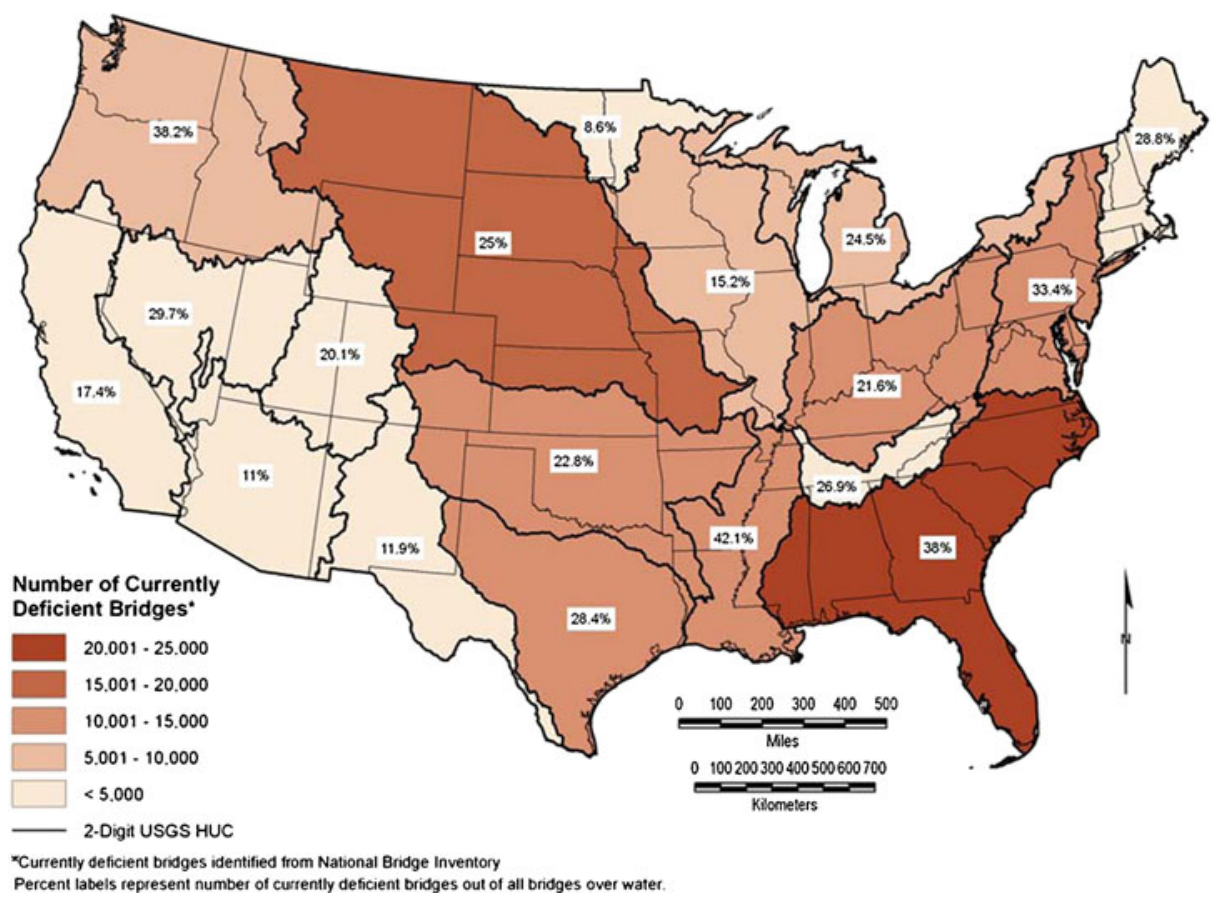

Fig. 2 Number and percentage of currently deficient bridges in the United States by 2-digit HUC

peak flow increases by $60 \%$, then all bridges on nonsandy soils would need strengthening of piers and abutments. For all bridges in sandy soils, peak flow would need to double $(100 \%$ increase) to require similar bridge strengthening.

We had two sets of assumptions on when riprap is applied to currently deficient bridges. Under one set, we assumed that the deficient bridges were brought up to current strength requirements prior to the start of the climate change impact. This may be an optimistic assumption given the number of bridges that are currently deficient. We also assumed that riprap is used to strengthen bridge foundations and that concrete is used to strengthen abutment foundations. Under the second set of assumptions, riprap would be applied to the currently deficient bridges as a response to climate change (as it would for currently acceptable bridges). Note that we consider deficient bridges to be vulnerable to a $20 \%$ increase in flow. Acceptable bridges would need a larger increase in flow to be considered vulnerable. If protective measures are not taken quickly in response to such a change, those bridges would be vulnerable to failure. The complete set of cost-estimating rules is provided in Table 2.

Table 1 Increase in flow that would make bridges vulnerable

\begin{tabular}{lll}
\hline Soil type & Current status & Change in flow \\
\hline Sandy & Deficient & $20 \%$ \\
Sandy & Acceptable & $100 \%$ \\
Nonsandy & Deficient & $20 \%$ \\
Nonsandy & Acceptable & $60 \%$ \\
\hline
\end{tabular}


Costs are assumed to be uniform across the country and were based on published cost data (RSMeans 2008) that are considered representative for the industry. Specifically, the cost for the adaptations is based on the elements required to construct either a riprap or foundation strengthening option. For the riprap option, the cost per ton of riprap is considered as a base that is then combined with an estimate of the total number of tons required to strengthen and protect the pier. A standard installation cost per ton is used to complete the estimate. Variance in both the installation and material costs can lead to variances in the final total. Similarly, for pier strengthening, costs were required for the construction process as well as the material and installation costs. The concrete strengthening approach is more expensive due to the need to construct coffer dams prior to adding the additional concrete around the pier foundations. Once again, variance in the cost of concrete as well as installation costs will lead to variances in the total cost in different geographic areas. However, the use of commercial cost data is considered an appropriate basis for the estimates presented here.

\section{Results}

\subsection{Number of bridges vulnerable to climate change}

The results of this analysis are provided in Table 3 and in Figs. 3 and 4. The table presents estimated numbers and percentages of bridges vulnerable to increases in 100-year peak flows. One notable result is that tens of thousands to more than 100,000 bridges are estimated to be at risk from climate change. The results vary considerably by time period and emissions scenario.

The number of at-risk bridges increases considerably from the mid-century to the late 21 st century. Consequently, 48,000 to 96,000 bridges are estimated to be at risk from an increase in the 100-year flow by 2055 (Fig. 3), depending on the emissions scenario, and 66,000 to 117,000 bridges are estimated to be vulnerable by 2090 (Fig. 4). These numbers represent about $10 \%$ to $20 \%$ of all bridges over water by mid-century and up to $25 \%$ of all bridges over water by late in the 21 st century. The number of bridges vulnerable to an increase in the 2-year event flow is of a similar magnitude.

The number of bridges vulnerable to climate change is sensitive to the level of greenhouse gas (GHG) emissions under future scenarios. For example, by 2055 the number of bridges vulnerable under the $\mathrm{A} 2$ scenario is double the number under the B1 scenario, and the number of bridges vulnerable under the A1B scenario is about half again as high as the B1 scenario.

The relative sensitivity of regions (see Fig. 1 for location of regions) varies depending on what statistics are examined. Regions 3 (the South Atlantic-Gulf), 5 (Ohio), 2 (Mid-Atlantic),

Table 2 Cost estimates, assuming all currently deficient bridges have an application of riprap to bring them up to strength requirements, as of ca. 2010

\begin{tabular}{|c|c|c|c|}
\hline \multicolumn{2}{|l|}{ Deficient, sandy } & \multicolumn{2}{|l|}{ Acceptable, sandy } \\
\hline $\begin{array}{l}\text { If the flow increase is }<100 \% \text {, } \\
\text { then do nothing because the } \\
\text { bridge has already been } \\
\text { strengthened using riprap. }\end{array}$ & $\begin{array}{l}\text { If the flow increase } \\
\text { is } \geq 100 \% \text {, then strengthen } \\
\text { the foundation footings } \\
\text { with concrete. }\end{array}$ & $\begin{array}{l}\text { If the flow increase } \\
\text { is }>20 \% \text { but }<100 \% \text {, } \\
\text { then strengthen with } \\
\text { riprap. }\end{array}$ & $\begin{array}{l}\text { If the flow increase } \\
\text { is } \geq 100 \% \text {, then strengthen } \\
\text { the foundation footings } \\
\text { with concrete. }\end{array}$ \\
\hline Deficient, nonsandy & & Acceptable, nonsandy & \\
\hline $\begin{array}{l}\text { If the flow increase is }<60 \% \text {, } \\
\text { then do nothing because the } \\
\text { bridge has already been } \\
\text { strengthened using riprap. }\end{array}$ & $\begin{array}{l}\text { If the flow increase } \\
\text { is } \geq 60 \% \text {, then strengthen } \\
\text { the foundation footings } \\
\text { with concrete. }\end{array}$ & $\begin{array}{l}\text { If the flow increase } \\
\text { is }>20 \% \text { but }<60 \% \text {, } \\
\text { then strengthen with } \\
\text { riprap. }\end{array}$ & $\begin{array}{l}\text { If the flow increase } \\
\text { is } \geq 60 \% \text {, then strengthen } \\
\text { the foundation footings } \\
\text { with concrete. }\end{array}$ \\
\hline
\end{tabular}


Table 3 Number of bridges vulnerable to increase in 100-year peak flow per 2-digit HUC. This includes bridges that are both currently deficient and within an 8-digit HUC where the projected peak flow from the 100-year, 24-hour storm exceeds the historical 100-year, 24-hour storm by 20\%; any bridge on sandy soils with a projected increase in modeled flow of greater than $100 \%$; or any bridge on nonsandy soils with a projected increase in modeled flow of greater than $60 \%$ for three future emissions scenarios (A2, A1B, B1) and two time periods $(2055,2090)$. Percentages are given in parentheses

\begin{tabular}{lccccrr}
\hline HUC & B1 2055 & A1B 2055 & \multicolumn{1}{c}{ A2 2055 } & B1 2090 & A1B 2090 & A2 2090 \\
\hline 1 & $1,428(13)$ & $3,026(28)$ & $2,430(22)$ & $2,726(25)$ & $2,720(25)$ & $2,904(27)$ \\
2 & $3,443(11)$ & $3,871(12)$ & $7,395(23)$ & $4,749(15)$ & $8,576(27)$ & $8,734(28)$ \\
3 & $6,860(11)$ & $7,772(12)$ & $15,106(24)$ & $3,987(6)$ & $19,552(31)$ & $23,072(36)$ \\
4 & $4,482(21)$ & $3,675(17)$ & $4,556(21)$ & $4,679(22)$ & $5,420(26)$ & $4,992(24)$ \\
5 & $6,350(11)$ & $8,458(14)$ & $11,996(20)$ & $10,156(17)$ & $13,480(22)$ & $12,654(21)$ \\
6 & $3,677(23)$ & $3,105(19)$ & $2,875(18)$ & $2,980(19)$ & $4,306(27)$ & $4,306(27)$ \\
7 & $5,591(10)$ & $6,030(11)$ & $7,246(13)$ & $4,354(8)$ & $8,409(15)$ & $8,129(15)$ \\
8 & $1,404(5)$ & $541(2)$ & $6,114(21)$ & $1,325(5)$ & $4,669(16)$ & $11,761(41)$ \\
9 & $343(8)$ & $221(5)$ & $351(9)$ & $325(8)$ & $359(9)$ & $351(9)$ \\
10 & $6,539(11)$ & $8,242(13)$ & $12,992(21)$ & $10,044(16)$ & $12,544(21)$ & $10,373(17)$ \\
11 & $925(2)$ & $1,648(3)$ & $5,812(12)$ & $4,612(9)$ & $5,481(11)$ & $6,764(14)$ \\
12 & $1,440(4)$ & $1,783(5)$ & $6,254(18)$ & $9,811(28)$ & $5,312(15)$ & $7,463(21)$ \\
13 & $291(6)$ & $566(12)$ & $1,258(26)$ & $1,077(22)$ & $869(18)$ & $1,868(38)$ \\
14 & $286(11)$ & $449(18)$ & $1,585(64)$ & $529(21)$ & $731(29)$ & $503(20)$ \\
15 & $126(2)$ & $288(4)$ & $1,645(23)$ & $306(4)$ & $619(9)$ & $1,824(26)$ \\
16 & $595(32)$ & $363(20)$ & $1,136(62)$ & $852(46)$ & $1,286(70)$ & $685(37)$ \\
17 & $1,672(11)$ & $2,694(18)$ & $4,930(33)$ & $3,036(20)$ & $4,415(30)$ & $8,216(55)$ \\
18 & $2,096(13)$ & $459(3)$ & $2,435(16)$ & $496(3)$ & $2,588(17)$ & $2,616(17)$ \\
Total & $47,548(10)$ & $53,191(11)$ & $96,116(20)$ & $66,044(14)$ & $101,336(21)$ & $117,215(24)$ \\
\hline
\end{tabular}

8 (Lower Mississippi), 10 (Missouri), and 17 (Pacific-Northwest) also have the most bridges that are potentially vulnerable to climate change.

The highest percentages of bridges found to be vulnerable are in different regions. In particular, Regions 14 (Upper Colorado), 16 (Great Basin), and 17 (Pacific Northwest) have relatively high percentages of bridges at risk in many of the scenarios. The percentages vary considerably by scenario and time period. This suggests that the rate of climate change is an important factor affecting vulnerability.

\subsection{Adaptation costs}

The cost estimation results should be interpreted with caution; the results suggest an order of magnitude of the costs of adapting the nation's bridges in response to climate change. Also, as noted above, many costs associated with harm to bridges, from traffic disruption to injury and loss of life, are not included in this estimate.

The estimated national costs for adapting vulnerable bridges to increased risks from climate change are displayed in Table 4 . Note that the costs are cumulative and are not expressed on an annualized basis. The costs are current costs, based on current construction and material costs, do not account for any real changes in prices, and are not in present-value terms.

The total costs for adapting bridges in response to the threats from climate change throughout the course of the 21 st century vary from approximately $\$ 140$ billion to 


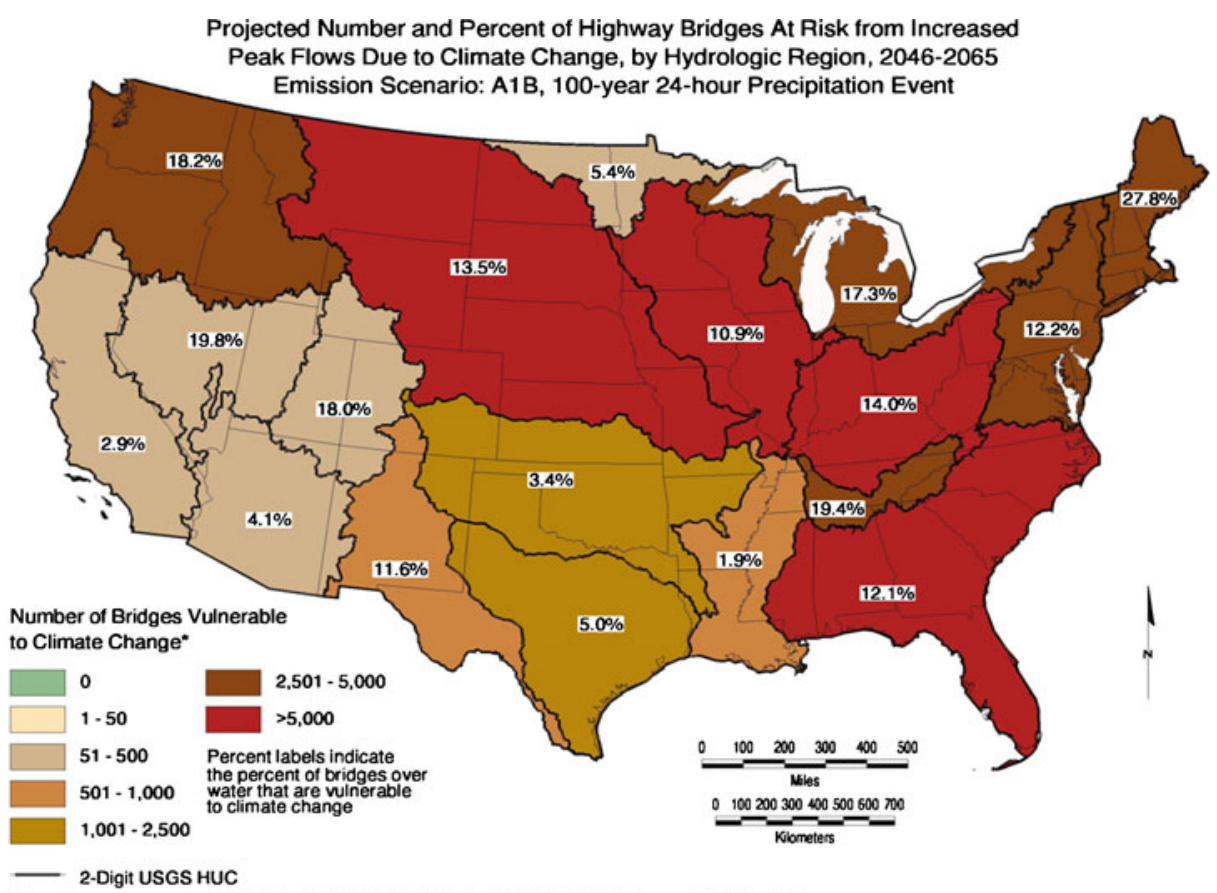

Based on Average of GCMs: CCCMA CGCM 3.1, CNRM CM3.0, and GFDL 2.0

*Includes currently deficient bridges identified from National Bridge Inventory and located within hydrologic regions with a projected increase in modeled flow of greater than 20 percent, plus currently acceptable bridges located on non-sandy soil with a projected increase in modeled flow of greater than 60 percent, plus currently acceptable bridges located on sandy soil with a projected increase in modeled flow of greater than 100 percent from time period 1981-2000 to 2046-2065.

Fig. 3 2046-2065, 100-year, 24-hour storm, Scenario A1B

approximately $\$ 250$ billion. The difference is a function of emissions scenarios and assumptions about adaptation. The A2 scenario results in approximately $40 \%$ more costs than the B1 scenario and approximately $15 \%$ more in adaptation costs than the A1B scenario.

Not only are the total costs affected by the magnitude of climate change but also by the burden of costs over time (displayed in Fig. 5). The faster the climate changes, the greater the share of adaptation costs are in the first half of the century. In the slowest warming scenario, B1, about three-fifths of the costs through 2090 are projected to be incurred before 2055. In contrast, more than four-fifths of the total costs of the highest GHG emissions scenario (A2) would be incurred by 2055 . Thus, the adaptation costs of the $\mathrm{A} 2$ scenario in the first 45 years are more than double the costs of the B1 scenario. Interestingly, so much is spent on the A2 scenario in the first period that the adaptation costs for the A2 scenario are lower than for the other two scenarios in the 2055-2090 period. However, this analysis does not account for higher maintenance and repair costs that may be incurred under accelerated investment scenarios such as A2. If the costs are spread out evenly over the century, the annual costs would be several billion dollars per year. The discussion above suggests that under some scenarios, annual costs in the first half of the century could be higher. In the A2 scenario, if spread evenly over the 2010-2055 period, annual costs could be $\$ 4$ to $\$ 6$ billion.

Costs are also sensitive to decisions on adaptation. The analysis suggests that if no steps are taken to strengthen currently deficient bridges, then the costs of adaptation rise by $27 \%$ to $28 \%$, regardless of the emissions scenario. For example, not making improvements to deficient bridges before climate change impacts are realized raises the total costs of adaptation under 


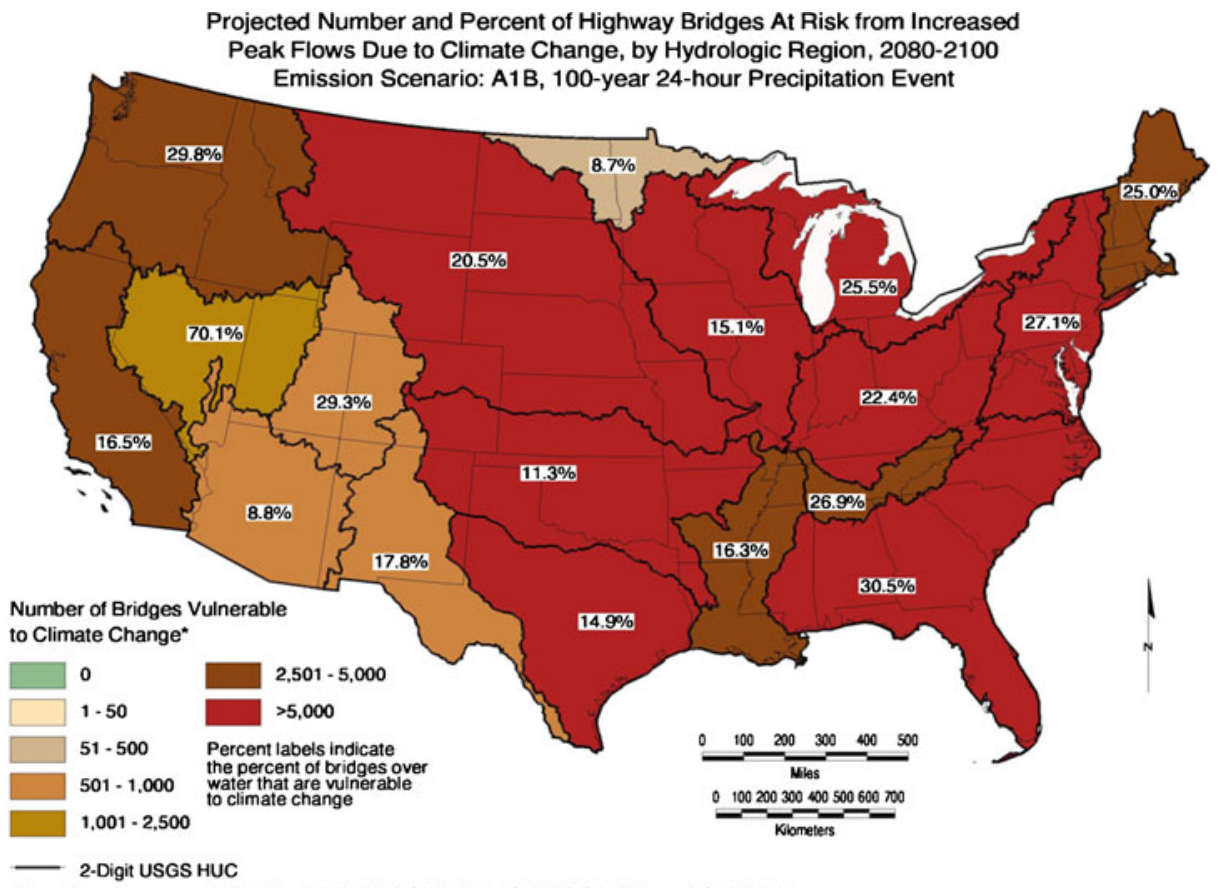

Based on Average of GCMs: CCCMA CGCM 3.1, CNRM CM3.0, and GFDL 2.0

*Includes currently deficient bridges identified from National Bridge Inventory and located within hydrologic regions with a projected increase in modeled flow of greater than 20 percent, plus currently acceptable bridges located on non-sandy soil with a projected increase in modeled flow of greater than 60 percent, plus currently acceptable bridges located on

sandy soil with a projected increase in modeled flow of greater than 100 percent from time period 1981-2000 to $2080-2100$.

Fig. 4 2080-2100, 100-year, 24-hour storm, Scenario A1B

the A1B scenario from $\$ 167$ to $\$ 213$ billion. This suggests that addressing current deficiencies in bridges, in addition to improving public safety, would also reduce adaptation costs.

\subsection{Limitations of analysis}

\subsubsection{Limitations of the hydrologic analysis}

The hydrologic methods used are documented and appropriate for large watersheds in the United States. TR-20 is a well-documented model based on a large volume of empirical data.

Table 4 Total costs for adapting vulnerable bridges to climate change ( $\$$ billions). Costs assume that either currently deficient bridges are repaired before climate change affects them or are repaired in response to climate change. Costs are cumulative for the period shown

Emissions scenario Deficient bridges repaired in advance of climate change

\begin{tabular}{lrrrrrrr}
\cline { 6 - 7 } & $2010-2055$ & $2055-2090$ & Total & & $2010-2055$ & $2055-2090$ & Total \\
\hline B1 & $\$ 72.1$ & $\$ 66.0$ & $\$ 138.1$ & $\$ 93.2$ & $\$ 82.2$ & $\$ 175.4$ \\
A1B & $\$ 97.4$ & $\$ 69.5$ & $\$ 166.9$ & $\$ 122.2$ & $\$ 90.8$ & $\$ 213.0$ \\
A2 & $\$ 150.9$ & $\$ 41.7$ & $\$ 192.6$ & $\$ 192.1$ & $\$ 55.3$ & $\$ 247.4$ \\
\hline
\end{tabular}

Deficient bridges repaired as adaptation to climate change 


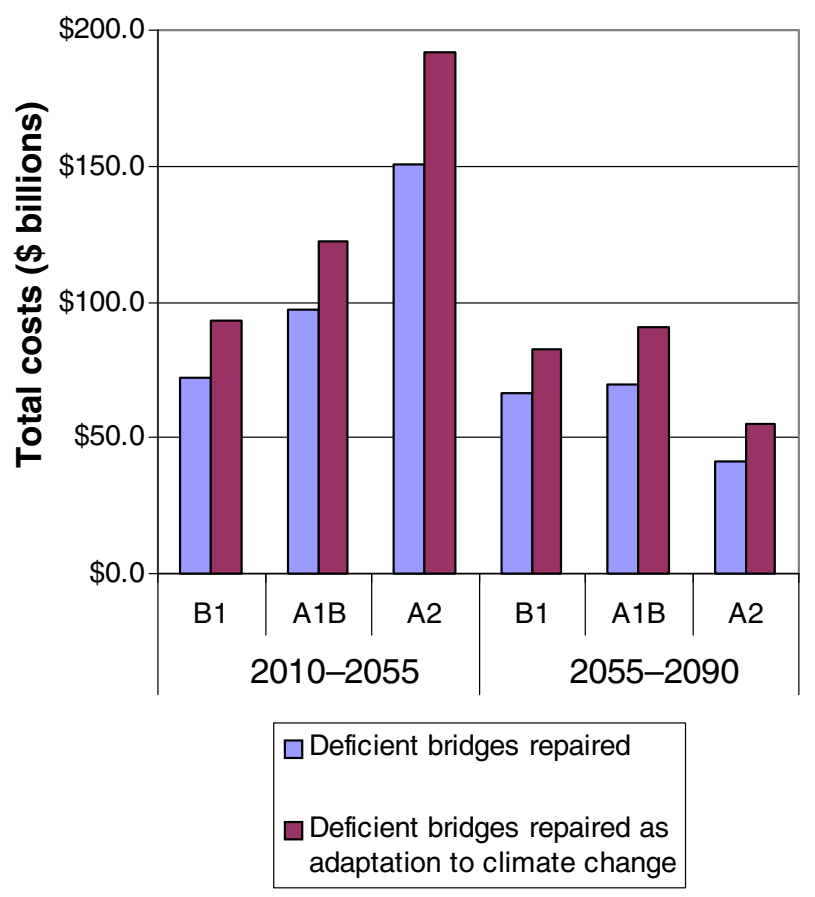

Fig. 5 Costs for adapting deficient bridges to climate change by time period and scenario. Proactive adaptation, for example, by strengthening currently deficient bridges, can reduce the total adaptation cost by nearly $30 \%$

The model was used only to predict changes from historical conditions based on changes in rainfall predicted by the various GCMs. Only rainfall was allowed to change in the analysis. Therefore, no land use changes were predicted and all other hydrologic conditions were assumed to remain unchanged. All errors in spatial datasets and hydrologic parameter estimation were assumed to affect the historic-conditions model identically to all future GCM-based simulations.

Several steps commonly performed in a watershed analysis were not done because of the need to model the entire continental United States. First, no intra-HUC modeling was performed. Therefore, flows in waterways upstream of the outlet of an HUC were not predicted, which in turn implies that actual flow under bridge locations was not simulated. Second, no routing, either hydrologic or hydraulic, was performed between HUCs. Therefore, mainstem flow rates in downstream HUCs were not simulated, again implying that flow rates were not simulated for any particular bridge location.

Because of these necessary conditions, the flow ratio results are best viewed as a "risk index," indicating locations where the probability of higher flow rates due to climate change is greater than in other areas of the country.

\subsubsection{Limitations of the climate change analysis}

The analysis used to estimate changes in extreme precipitation from GCMs has a number of limitations. GCMs in general do not simulate precipitation well. One reason for this is that GCMs simulate the world in grid boxes that can be anywhere from 100 to several hundred 
miles across. Precipitation can be highly localized. This is particularly the case for convective storms, which are one source of flooding. At best, GCMs can parameterize such storms.

Twenty-year time slices were used to estimate the 100-year, 24-h precipitation events (using Log Pearson). Such a time period is relatively short when estimating change in extreme events, particularly the 100-year event. As noted in the discussion of the results, it is possible that the short time period leads to some peculiar regional results.

\subsubsection{Limitations of the vulnerability analysis}

The study assumed that certain percentage increases in peak flow would make all bridges in the same class vulnerable. Selection of different thresholds could significantly change the quantitative results. In addition, the vulnerability of actual bridges is likely to vary, thus different changes in flow would lead to vulnerability.

The impact on the bridges is based on the information provided in the National Bridge Database. The size of the bridge, number of lanes and piers, and traffic levels are also taken from that source. Adaptations and vulnerabilities for an individual bridge are based on the observations and data recorded in the database. Given the information provided, design adaptations are calculated based on the anticipated flow increases. All adaptations are subject to the accuracy of the information contained in the database.

Increased flooding implies increased frequency and magnitude of flow rates and in turn channel velocities and scour potential. The methods used are purely based on the potential change in scour potential. The methods do not consider the physical impact of a bridge's current condition on the severity of impact on that bridge, that is, the same increase in scour potential results in the same cost whether the bridge is currently in adequate or inadequate condition.

Note that the ratings of bridges show their current status. Our analysis is for impacts throughout the 21 st century. Clearly, there will likely be significant changes to the nation's bridges during that time. Some bridges will be strengthened, some will deteriorate, some will be removed, and new bridges will be built. Rather than speculate about such changes, we based the analysis on the current state of the nation's bridges and essentially assumed that the infrastructure will not change in the future.

\subsubsection{Limitations of the cost analysis}

Many simple assumptions were made in the cost analysis. First, it was assumed that the same adaptations are made to all bridges vulnerable to climate change. The first set of adaptations is to add riprap to piers. The second set is to strengthen piers and abutments. The same increase in flow levels triggers the adaptations. Just as the level of change in peak flow needed to justify adaptations will differ from site to site and from bridge to bridge, in all likelihood, adaptations will differ or vary from bridge to bridge. Even within general types of measures (riprap versus strengthening), actual measures will differ as well. Costs are also assumed to be uniform across the country, which is an oversimplifying assumption.

We also assumed that adaptations are made before bridges are damaged as the result of climate change. We assume that climate changes are anticipated and that adaptation investments are made in a timely manner. These assumptions are, to put it mildly, heroic. Given the relative high percentage of bridges that are deficient, it would take an extraordinary change in fiscal priorities to address current risks as well as risks from climate change.

On the whole, the estimate of the costs of adaptation may be optimistic, and actual costs could be higher than what is estimated in this report. 


\section{Conclusions}

This study involved applying top-down techniques to estimate the vulnerability of bridges in the lower 48 states to potential increases in peak river flow and the costs of adapting this important infrastructure. Our purpose was to present an initial indication of the potential vulnerability of the nation's transportation network to climate change and the costs of adapting this network. The results should be treated as indicative of vulnerability and costs. More estimates will require more detailed and site-specific analyses.

Bridges will differ in their vulnerability to climate change. The current analysis found that about one-fourth of the more than 500,000 bridges in the dataset are currently deficient and thus are more vulnerable to climate change (and variability) than other bridges.

A key variable in this analysis is the amount of increase in the magnitude of 100-year, 24-h storms that would threaten bridges. We assumed the same percentage increase would threaten all bridges in the same class (i.e., deficient, acceptable on sandy soils, and acceptable on nonsandy soils). The specific amount will likely vary on a bridge-by-bridge basis. The assumptions we applied may be conservative, as smaller increases in flow may cause problems for many bridges.

More than 100,000 of the nation's bridges are estimated to be vulnerable to climate change. The results vary by emissions scenario, with the higher emissions scenario leading to more bridges becoming vulnerable. In addition, more bridges are likely to become vulnerable sooner under the highest emissions scenario than under the lowest emissions scenario.

The total costs for adapting the bridges to the increased peak flow risks range from approximately $\$ 140$ to $\$ 250$ billion. The highest emissions scenario increases costs by about $40 \%$ over the lowest emissions scenario. Decisions to improve currently deficient bridges before the effects of climate change are realized can reduce adaptation costs by approximately $30 \%$.

This estimate provides an indication of the potential impact of climate change to bridges in the United States. However, climate change is a global phenomenon and thus could affect the integrity of bridges around the world. The study documented in this paper can be replicated in both developed and developing countries to estimate potential impacts. We expect that older bridges that have not been adequately maintained may, as indicated in this study, be found to be at particular risk from climate change. A key factor in assessing vulnerability will be the extent to which intense precipitation is projected to increase. Protection of particularly vulnerable bridges should be considered.

In general, the study shows that vulnerability and adaptation costs are sensitive to the amount of GHGs emitted and the way in which the infrastructure is managed. These results should be interpreted with caution because the analysis of climate change and bridge vulnerability has many limitations. Nonetheless, the study indicates that many U.S. bridges could be at significant risk from the effects of climate change and adaptation costs could be hundreds of billion of dollars throughout the 21 st century. Similarly, the study provides a framework that can be used to assess the potential impacts of climate change in other countries and regions of the world.

Acknowledgments We acknowledge the support of the U.S. Environmental Protection Agency's Office of Atmospheric Programs, Climate Change Division, contract EP-W-07-072. The views expressed in this document are solely those of the authors and do not necessarily reflect those of the Agency. We also acknowledge the support in producing the paper provided by Diane Callow, Erin Miles, Mary Kay Kozyra, Laura Cross, and Laura Sims of Stratus Consulting. 


\section{References}

ASCE (1992) Design and construction of urban stormwater management systems. American Society of Civil Engineers Manual of Practice No. 77

Ashley R, Blanksby J, Cashman A, Jack L, Wright G, Packman J, Fewtrell L, Poole A (2009) Adaptable urban drainage - addressing change in intensity. http:/www.atypon-link.com/ALEX/doi/pdf/10.2148/ benv.33.1.70? cookieSet $=1$. Cited 18 Oct 2010

AUSTROADS (2004) Impact of climate change on road infrastructure. Austroads Publication No. AP - R243/ 04, Sydney, Australia

Bedient P, Huber W, Vieux BE (2008) Hydrology and floodplain analysis, 4th edn. Prentice Hall, Upper Saddle River, pp 171-209

Briaud J-L (2006) Bridge scour and the structural engineer. Structure December:58-61

Chinowsky PS, Strzepek K, Larsen P, Opdahl A (2009) Adaptive climate response cost models for infrastructure. J Infrastruct Syst, ASCE 16(3):173-225

Chinowsky PS, Hayles C, Schweikert A, Strzepek N (2011a) Climate change as organizational challenge: comparative impact on developing and developed countries. Eng Proj Organ J 1(1):57-64

Chinowsky PS, Schweikert A, Strzepek N, Manahan K, Strzepek K, Schlosser CA (2011b) Adaptation advantage to climate change impacts on road infrastructure in Africa through 2100. Discussion paper, UNU-WIDER, Helsinki, Finland

Dent S, Wright L, Mosley C, Housen V (2000) Continuous simulation vs. design storms, comparison with wet weather flow prediction methods. Proc of the Water Env. Federation, Collection Systems. (20):373-392

FHWA (2001) Evaluating scour at bridges, 4th ed. National Highway Institute. Publication No. FHWA NHI 01-001. Hydraulic Engineering Circular No. 18. Federal Highway Administration, Washington, DC

FHWA (2009a) Bridge scour and stream instability countermeasures: Experience, selection, and design guidelines, 3rd edn. National Highway Institute. Publication No. FHWA NHI 09-111. Hydraulic Engineering Circular No. 23. Federal Highway Administration, Washington, DC

FHWA (2009b) 2008 NBI ASCII files. Federal Highway Administration. http://www.fhwa.dot.gov/bridge/ britab.cfm. Cited 8 April 2009

Galbraith RM, Price DJ, Shackman L (2005). Scottish road network climate change study. Scottish Executive Hewitson B (2003) Developing perturbations for climate change impacts assessment. Eos 84(35):337-348

James W (1994) On reasons why traditional single valued, single event hydrology (typical design storm method) has become simple-minded, dishonest, and unethical. US Army Corps of Engineers, Workshop on Urban Hydrology and Hydraulics, Davis, CA. 169-181

Johns TC, Durman CF, Banks HT, Roberts MJ, McLaren AJ, Ridley JK, Senior CA, Williams KD, Jones A, Rickard GJ, Cusack S, Ingram WJ, Crucifix M, Sexton DMH, Joshi MM, Dong B-W, Spencer H, Hill RSR, Gregory JM, Keen AB, Pardaens AK, Lowe JA, Bodas-Salcedo A, Stark S, Searl Y (2006) The new Hadley Centre climate model HadGEM1: evaluation of coupled simulations. J Clim 19:1327-1353

Larsen P, Goldsmith S, Smith O, Wilson M, Strzepek K, Chinowsky P, Saylor B (2008) Estimating future costs for public infrastructure at risk from climate change. Global Environ Change 18(3):442-457

Mailhot A, Duchesne S (2010) Design criteria of urban drainage infrastructures under climate change. J Water Res Plan Manage 136(2):201-208

Nakićenovic N, Alcamo J, Davis G, de Vries B, Fenhann J, Gaffin S, Gregory K, Grubler A, Jung TY, Kram T, La Rovere EL, Michaelis L, Mori S, Morita T, Pepper W, Parry H, Canziani O, Palutikof JP, Hanson C, van der Linden P (eds) (2000) Climate change 2007: impacts, adaptation and vulnerability. Contribution of Working Group II to the Fourth Assessment Report of the Intergovernmental Panel on Climate Change. Cambridge University Press, New York

NRC (2008) Potential impacts of climate change on U.S. transportation. National Research Council. Transportation Research Board, Washington, DC

NRC (2010) America's climate choices: Panel on adapting to the impact of climate change. National Research Council. The National Academies Press, Washington

Parry ML, Canziani O, Palutikof JP, Hanson C, van der Linden P (eds) (2007) Climate change 2007: Impacts, adaptation and vulnerability. Contribution of Working Group II to the Fourth Assessment Report of the Intergovernmental Panel on Climate Change. Cambridge University Press, New York

Randall DA, Wood RA, Bony S, Colman R, Fichefet T, Fyfe J, Kattsov V, Pitman A, Shukla J, Srinivasan J, Stouffer RJ, Sumi A, Taylor KE (2007) Climate models and their evaluation. In: Solomon S, Qin D, Manning M, Chen Z, Marquis M, Averyt KB, Tignor M, Miller HL (eds) Climate change 2007: the physical science basis. Contribution of Working Group I to the Fourth Assessment Report of the Intergovernmental Panel on Climate Change. Cambridge University Press, Cambridge, United Kingdom and New York, NY, USA

Richardson E, Lagasse P (1998) Stream stability and scour at highway bridges. ASCE 
RSMeans (2008) Heavy construction cost data. Reed Construction Data, Norwell

Savonis MJ, Burkett VR, Potter JR, Kafalenos R, Hyman R, Leonard K (2009) The impact of climate change on transportation in the Gulf Coast. TCLEE 2009: Lifeline earthquake engineering in a multihazard environment. ASCE, Reston

Solomon S, Qin D, Manning M, Chen Z, Marquis M, Averyt KB, Tignor M, Miller HL (eds) (2007) Climate change 2007: The physical science basis. Contribution of Working Group I to the Fourth Assessment Report of the Intergovernmental Panel on Climate Change. Cambridge University Press, New York

Stedinger JR, Vogel DR, Foufoula-Georgiou E (1993) Frequency analysis of extreme events. In: Maidment D (ed) Handbook of hydrology. McGraw-Hill, New York, pp 17.1-17.55

TRB (2008) Potential impacts of climate change on U.S. transportation. TRB Special Report 290. Transportation Research Board, Washington, DC

USDOT FHA (1995) Recording and coding guide for the structural inventory and appraisal of the nation's bridges. Office of Engineering, Bridge Division. Report number FHWA-PD-96-001

USGS (2009) Hydrologic unit map (based on data from USGS Water-Supply Paper 2294). http://water.usgs. gov/GIS/regions.html. Cited 14 July 2009

Wigley TML (2008) MAGICC/SCENGEN 5.3: User manual. National Center for Atmospheric Research, Boulder, CO. http://www.cgd.ucar.edu/cas/wigley/magicc/

Wilbanks TJ, Romero Lankao P, Bao M, Berkhout F, Cairncross S, Ceron J-P, Kapshe M, Muir-Wood R, Zapata-Marti R (2007) Industry, settlement and society. Climate change 2007: Impacts, adaptation and vulnerability. In: Parry ML, Canziani OF, Palutikof JP, van der Linden PJ, Hanson CE (eds) Contribution of Working Group II to the Fourth Assessment Report of the Intergovernmental Panel on Climate Change. Cambridge University Press, Cambridge, pp 357-390

Xanthakos PP (1995) Bridge substructure and foundation design. Prentice-Hall, Saddle River 